\title{
ENSINO SUPERIOR EM TEMPOS MEDIADOS PELAS TECNOLOGIAS DIGITAIS
}

\author{
Higher education in times mediated by digital technologies
}

\author{
KENSKI, Vani Moreira ${ }^{1}$ \\ MEDEIROS, Rosangela Araújo² \\ ORDÉAS, Jean ${ }^{3}$
}

\section{Resumo}

O mundo mudou. As relações humanas e as relações com a informação e o conhecimento mudaram. A ampliação do acesso à internet e às tecnologias digitais estabeleceram novos patamares de relacionamento entre pessoas, processos e objetos. Essas mudanças afetam também as instituições de ensino, que precisam se reinventar para não ficarem à margem dessa evolução. Um dos desafios contemporâneos é saber escolher a informação e transformá-la em conhecimento significativo, algo completamente diferente de pelo menos duas décadas atrás, quando o desafio era obter a informação. Hoje a informação é abundante. O acesso ao excesso (COSTA, 2008) de informação é possível em qualquer localidade e horário. Gera novas necessidades de orientação docente e de participação dos estudantes. Discutimos esse contexto de mutação do saber a partir de Levy (1999) e Santos (2005), que nos ajudam a compreender esse processo e a posição que a universidade assume nesse novo cenário. Garcia et al. (2011), Santaella (2013) e Kenski (2015) trazem para a discussão as novas relações, formas e estratégias de ensino e aprendizagem mediadas de acordo com os novos anseios formativos dos sujeitos e da sociedade contemporânea. Assim, o objetivo deste texto é apresentar reflexões sobre as tecnologias digitais e as necessidades de mudança no processo educacional desenvolvido pelas instituições de ensino superior brasileiras.

Palavras-chave: Ensino superior. Cultura digital. Tecnologias digitais.

\begin{abstract}
The world changed. Human relations and relations with information and knowledge have changed. The expansion of Internet access and digital technologies have established new levels of relationship between people, processes and objects. These changes also affect educational institutions, which need to reinvent themselves so as not to be left out of this evolution. One of the contemporary challenges is to choose information and turn it into meaningful knowledge, something completely different from at least two decades ago when the challenge was to get the information. Today the information is plentiful. Access to excess information (COSTA, 2008) is possible in any location and time. It generates new needs for teaching orientation and student participation. We discuss this context of knowledge mutation from Levy (1999) and Santos (2005), which help us to understand this process and the position the university takes in this new scenario. Garcia et al. (2011), Santaella (2013) and Kenski (2015) bring to the discussion the new relationships, forms and strategies of teaching and learning mediated according to the new formative longings of subjects and contemporary society. Thus, the purpose of this text is to present reflections on the digital technologies and the needs of change in the educational process developed by the Brazilian higher education institutions.
\end{abstract}

Keywords: Higher education. Digital culture. Digital Technologies.

\footnotetext{
${ }^{1}$ Doutora e Mestre em Educação. Licenciada em Pedagogia e Geografia. Vice-presidente da ABED (Associação Brasileira de Educação a Distância), gestão 2015-2019. Professora do Programa de Pós-Graduação em Educação da Universidade de São Paulo (USP). E-mail: <vanikenski@gmail.com>

${ }^{2}$ Doutoranda em Educação pela Universidade de São Paulo (USP). Mestre e Pedagoga pela USP. Professora da Universidade do Estado da Paraíba. E-mail: < professorarosangelauepb@gmail.com >

${ }^{3}$ Mestrando em Educação pela Universidade de São Paulo (USP). Especialista em Educação a Distância pela Universidade Federal do Ceará (UFC). Possui graduação em Pedagogia pela Universidade Estadual do Ceará (UECE). É membro associado da Associação Brasileira de Educação a Distância - ABED. E-mail: <jean.ordeas@gmail.com>
}

Trabalho \& Educação | v.28 | n.1 | p.141-152 | jan-abr | 2019 


\section{INTRODUÇÃO}

Tecnologias diversas acompanham a humanidade em todas as eras. Criadas como extensões das capacidades humanas, elas se apresentam como artefatos úteis para viver melhor, de acordo com as concepções do que seja o "melhor" em cada época, cada cultura, cada espaço e cada condição social, econômica e cultural vivenciada. Assim, as relações entre tecnologias e qualidade de vida dependem de aspectos que extrapolam suas criações e seus usos. Martelos, livros ou armas são utilizados de formas diversas - para sobreviver, aprender ou se divertir - por diferentes pessoas e sociedades.

E chegamos às tecnologias mais atuais da civilização, as digitais. Distintas, elas se atualizam e se multiplicam exponencialmente. Acessíveis à maioria das pessoas, são cada vez mais intuitivas, fáceis de manusear e se incorporam - não como modismo, mas como necessidade - à realidade cotidiana de nossas vidas. Diferentes das demais, tais tecnologias agregam recursos, técnicas e metodologias anteriores que convergem e se atualizam na lógica da cultura digital (KENSKI, 2018). Dispersivas, ubíquas e pervasivas, criam vínculos e vícios pessoais e sociais: não conseguimos mais viver sem elas.

O fascínio tecnológico da era do digital não está, no entanto, na materialidade dos equipamentos e recursos que Ihes viabiliza a existência. Ele transcende o contexto maquínico e mesmo as propriedades técnicas, sempre em atualização. Seu poder maior está na realização do anseio humano de completude, de pertencimento, ainda que virtual, mas real. O digital viabiliza o encontro com outros seres - humanos e não humanos - com os quais é possível comunicar, interagir, perguntar, responder, planejar... criar, juntos.

Essas possibilidades da cultura digital envolvem camadas tecnológicas distintas, de acordo com os avanços e inovações apresentadas pelos meios (ou mídias) de interação, comunicação ou desenvolvimento de novos comportamentos, processos e produtos. A Internet como ponto de convergência das múltiplas camadas das tecnologias digitais, em suas poucas décadas de existência plena, tornou possível a formação de redes e o acesso aberto a informações por toda a sociedade. Uma nova tecnologia digital é ponto de partida para a criação de inúmeras outras tecnologias, mais potentes, diferentes e que ampliam a capacidade humana de ir além do conhecido e vivenciado até então.

O resultado dessa (re)volução tecnológica intensa que avança em poucas décadas para seu quarto estágio está na "convergência dos mundos físico, digital e biológico que [...] oferece oportunidades significativas para o mundo alcançar enormes ganhos em uso e eficiência de recursos" (KLAUS, 2016, p. 63). Dessa convergência é possível elencar diversos produtos que têm condições de causar alterações profundas nos processos educacionais, tais como a impressora 3D, inteligência artificial, internet das coisas, armazenamento em nuvem, entre outros, que podem trazer benefícios nunca antes experimentados aos processos educacionais, desde que as instituições se preparem para acompanhar e fazer parte dessa evolução.

Assim, alcançamos um novo patamar tecnológico, da cultura digital: o do uso intensivo de mídias interativas e móveis. Ou seja, tecnologias ubíquas, que podem funcionar em qualquer tempo e local conectável. Como mídias de síntese, incorporam antigos meios tecnológicos - imagens, vídeos, sons, textos... - e, em múltiplas interfaces, fazem-nos 
ir além. Nas relações sociais nos fazem convergir para pontos comuns de conversas e reflexões pessoais e coletivas com os nossos pares, colegas, amigos, parceiros... o mundo inteiro, o conhecimento acumulado, saberes e crenças. Mais ainda, tornamonos produtores de informações acessáveis e intercambiáveis com todos. Somos múltiplos na cultura digital e somos próximos de tudo e todos pelas mídias móveis.

Para termos uma ideia da dimensão que as mídias móveis ocupam na sociedade, a última pesquisa sobre o uso de Tecnologias de Informação e Comunicação nos domicílios brasileiros - TIC Domicílios, publicada pelo Centro Regional de Estudos para o Desenvolvimento da Sociedade da Informação - CETIC em 2017, indica que 92\% das habitações brasileiras possuem telefone celular, 29\% computador portátil, 23\% computador de mesa e $16 \%$ tablet. Se considerarmos os meios de acesso à internet ${ }^{4}$, por indivíduo, veremos que $96 \%$ acessam via celular, 33\% via Notebook, 30\% por meio de computador de mesa e outros 15\% via tablet (CETIC, 2017). Esses dados confirmam a predominância do uso de dispositivos móveis, favorecendo a ubiquidade e a possibilidade de acesso instantâneo, a qualquer tempo e lugar. Essa conexão contínua favorece a formação de redes e reforça a necessidade de reflexão sobre a importância da internet e das tecnologias digitais na sociedade, e de um modo especial na educação e no ensino superior.

Formamos redes com pessoas conhecidas e desconhecidas que estão em locais próximos e distantes. Unidos por interesses comuns, formatamos as redes como comunidades nas quais conversamos sobre os mesmos temas, refletimos e discutimos assuntos do nosso interesse, ensinamos e aprendemos muito, com todos os nossos parceiros online, onde quer que estejam conectados. A possibilidade de colóquios permanentes nos fascina e cria o sentimento de pertencimento, na convergência de pessoas que nos complementam. Somos muitos, somos um.

O processo de aprendizagem desencadeado nas redes tem suas especificidades. Intuitivamente somos guiados pela curiosidade e motivação para buscar informações sobre o que nos interessa. São muitos os casos de jovens que aprendem sozinhos a se comunicar em outros idiomas, para avançarem em jogos e desafios internacionais. Essas são as primeiras regras para a aprendizagem nos meios digitais. Há que estar motivado para aprender e ir em busca do conhecimento.

Nas horas livres, aprendizes de todas as idades e escolarização superam dificuldades e aprendem a manejar seus equipamentos móveis para interagir, comunicar, expressar-se, divertir e se informar. Nos espaços regulares de formação, no entanto, essa prática é pouco utilizada. A escola de todos os níveis ainda não aproveita de forma satisfatória as potencialidades do digital para o uso pedagógico nos processos de formação de todos os participantes, professores e estudantes, principalmente.

Esse descompasso entre o aproveitamento do potencial pedagógico das tecnologias digitais e os processos de ensino e aprendizagem na universidade reflete a necessidade urgente de adequar os currículos dos cursos de formação de professores, estrutura de apoio tecnológica e física das instituições, dotando-as de laboratórios, redes de conexão de alta velocidade e espaços pedagógicos adequados ao desenvolvimento de atividades mediadas pelas tecnologias digitais. Sem essas

\footnotetext{
${ }^{4} \mathrm{~A}$ soma dos percentuais ultrapassa os $100 \%$ pois é levado em consideração que um mesmo indivíduo pode ter acesso à internet por mais de uma mídia. 
mudanças básicas, as Instituições de Ensino Superior (IES) não conseguirão reduzir o gap entre a demanda da sociedade conectada e a formação oferecida.

Esse distanciamento entre o espaço formativo regular das universidades e o uso prático e intensivo das tecnologias digitais, sobretudo as móveis, para ensinar e aprender precisa ser repensado, discutido e superado.

\section{LACUNAS ENTRE DESENVOLVIMENTO TECNOLÓGICO E A REALIDADE SOCIAL BRASILEIRA}

A sociedade brasileira vive diferenciados níveis de desenvolvimentos e integrações com as tecnologias e a cultura do digital. Enquanto alguns espaços sociais acompanham e protagonizam as mudanças e evoluções das tecnologias de última geração, outros recantos do País estão à margem das tecnologias mais avançadas e suas funcionalidades. Vários são os fatores - econômicos, sociais e culturais - que contribuem para a existência dessas disparidades e de lacunas tecnológicas na realidade social. No Brasil, a condição e qualidade de acesso à internet, por exemplo, está condicionada a classe social e região. Pesquisa realizada pelo Comitê Gestor da Internet no Brasil - CGI.Br (2018) indica que, no ano de 2015, 78\% daqueles que estão situados no maior quintil de renda per capita têm acesso à internet, enquanto apenas $44 \%$ dos que se encontram no no grupo de renda mais baixa possuem acesso à internet, independentemente do meio ou dispositivo que utilizam para acessar.

No que concerne aos acessos por região no Brasil, a Figura 1 apresenta a CentroOeste como aquela mais conectada enquanto as regiões Norte e Nordeste possuem índices menores de conexões por usuário.

Figura 1 - Porcentagem de usuários de internet por região no Brasil

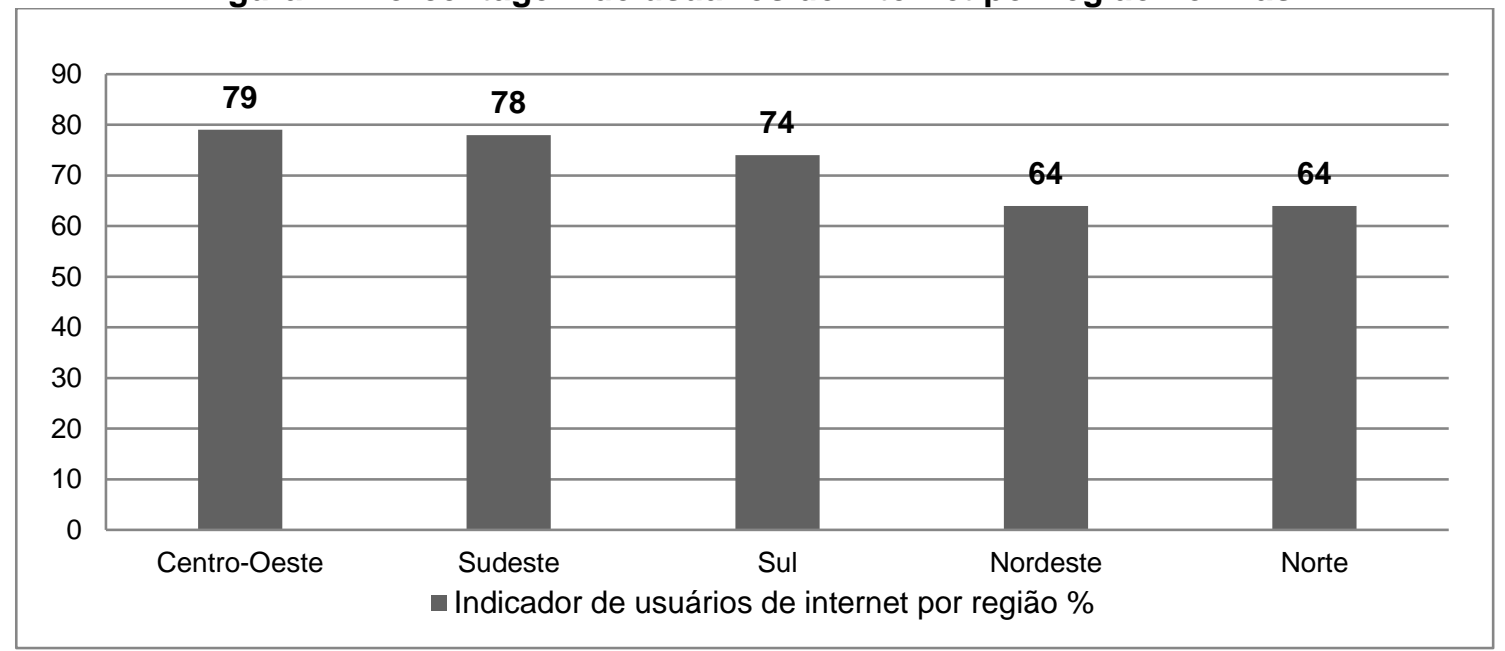

Fonte: CGI.br/NIC.br - TIC domicílios 2017

Ainda no campo do uso de internet por domínio geográfico, a mesma pesquisa indica que $64 \%$ dos habitantes das áreas urbanas usam internet, enquanto nas áreas rurais, esse número chega a $26 \%$. O estudo do $\mathrm{CGI} . \mathrm{Br}$ avalia que esse cenário de disparidade de acesso exige medidas reparadoras como forma de incluir a parcela da população privada do acesso à internet. "A penetração da rede é mais reduzida em áreas rurais e em determinadas regiões geográficas, o que indica a necessidade de 
esforços para a conectividade de setores importantes da população" (GCI.Br, 2018, p. 68).

Quando se compara o acesso à internet com o grau de instrução dos indivíduos, também é possível notar a correlação entre formação e acesso. No Brasil, 93\% das pessoas com o ensino superior completo usam internet, enquanto apenas $29 \%$ das pessoas com o primário incompleto acessam a rede, segundo relatório do Comitê Gestor da Internet no Brasil (2018), para o qual "esse resultado corrobora o chamado viés de habilidades da Internet, cujo aproveitamento tende a favorecer aqueles com maior capital humano" (p. 36).

Nessa perspectiva, o relatório internacional produzido pelo New Media Consortium, em parceria com a Educause Learning Initiative (ELI), de publicação anual, intitulado "Horizon Report", apresenta os principais desafios, tendências e evoluções das tecnologias digitais nos sistemas de ensino, inclusive no nível superior. Na edição de 2017, um dos desafios apontados para a adoção de tecnologias na educação superior seria o avanço na equidade digital. O estudo indicou que:

Apesar da proliferação de tecnologia e materiais de aprendizagem on-line, o acesso ainda é desigual. Lacunas persistem em todo o mundo que estão dificultando a conclusão da faculdade para grupos de estudantes por status socioeconômico, raça, etnia e gênero. Além disso, o acesso à Internet suficiente permanece desigual (ADAM BECKER et al., 2017, p. 2).

Conhecer esse cenário macro possibilita ter a clareza de que a lacuna tecnológica existente na universidade não se resolve apenas com a inclusão de recursos digitais nas salas de aula e nos laboratórios. É necessário um conjunto de políticas públicas integradas, que possibilitem o domínio amplo dos meios digitais por todos os brasileiros. Para isso são necessários programas massivos de inclusão e letramento digital para a população que, a despeito de possuir acesso às tecnologias digitais cotidianamente, ainda não possui formação e conhecimentos básicos para a sua adequada e transformadora apropriação.

\section{O ENSINO SUPERIOR NA CULTURA DIGITAL}

O ensino superior está imerso em grandes desafios, tendo em vista as demandas e tendências desse novo contexto tecnológico. Estão em xeque a estrutura, o currículo, os espaços, os tempos e os modelos de ensino e de aprendizagem utilizados até então, bem como os papéis desempenhados por docentes e estudantes na relação com o conhecimento socialmente válido.

Entre todos os espaços regulares de formação educacional, a universidade se apresenta como instituição máxima de desenvolvimento de profissionais e pesquisadores. Cabe a ela a responsabilidade de viabilizar a formação plena de seus estudantes, de acordo com as necessidades da sociedade em que está inserida. A correspondência biunívoca entre a universidade e a cultura local está diretamente ligada às pessoas que transitam permanentemente nesses dois lugares: universidade e espaço social que habitam. Elas são as mesmas e se utilizam das mídias digitais para as mais diversas ações em suas vidas cotidianas.

O túnel do tempo presente nas liturgias das salas de aula universitárias se encarrega de apartar as funcionalidades do digital dos ritos pedagógicos das aulas que, 
tradicionalmente, permanecem na antiga cultura da comunicação em massa. Professores detêm o poder e o saber e o anunciam seletivamente para os estudantes, que o replicam, como caixas de ressonância distribuídas.

Levy (1999) pontua que vivenciamos uma mutação na relação com o saber. Os universitários possuem novos interesses e habilidades, sobretudo nos usos dos recursos digitais. Não se interessam em permanecer em aulas massivas - plenas do protagonismo do docente e a passividade dos estudantes - cujos objetivos estão ligados à reprodução de conteúdos, de acordo com a perspectiva apresentada pelo mestre. Exigem outros modos de ensino, mais velozes e participativos. Por meio de seus equipamentos digitais móveis acessam informações e interagem com o resto do mundo em busca de saberes que estão disponíveis em qualquer lugar. Mídias inteligentes conectadas à internet que não conferem somente mobilidade $\mathrm{e}$ convergência. Oferecem também versatilidade e rapidez em interações amplas, no acesso a informações e em tomada de decisões em diferentes âmbitos da vida, o que exige novas habilidades.

Em termos ideais, espaços de ensino e de aprendizagem no ensino superior deveriam contribuir minimamente para que os estudantes desenvolvessem capacidades de selecionar, mapear e articular a informação disponível no ciberespaço com as estruturas cognitivas e culturais de que os estudantes dispõem. A universidade urge também formar sujeitos que saibam colaborar e viver situações de compartilhamento em contextos discursivos diversos, preparados para a "improvisação, a imprevisibilidade, a indeterminação, a criatividade e a inovação".

A cultura digital vigente na sociedade do século 21 estabelece uma revolução antropológica (GARCIA et al., 2011), mais do que tecnológica. A intersecção entre mundo offline e online institui novas configurações nas relações de ensino, que deve ser aberto, ubíquo (SANTAELLA, 2013), em formatos que misturam situações presenciais e online. É tempo de provocar conexões entre pessoas, objetos, máquinas, saberes e ideias.

É nesse sentido que Kenski (2015) assevera sobre as mudanças desencadeadas pelas tecnologias digitais no processo de ensino e aprendizagem no ensino superior, que "engloba o uso de novas estratégias didáticas e, um ponto essencial, maior interação com os estudantes e as realidades para as quais eles estão sendo formados" (p. 458).

Não se trata só do domínio técnico de ferramentas digitais específicas ou de funcionalidades de Learning Management System (LMS), que normalmente são estruturados em Ambientes Virtuais de Aprendizagem (AVA). As mudanças são velozes, inclusive nos dispositivos e ferramentas. O que hoje é utilizado no smartphone ou no Moodle (um AVA de origem gratuita e com linguagem aberta, muito utilizado nas instituições universitárias), meses depois já pode ter sido modificado, ou se tornou obsoleto, pouco veloz ou pouco eficaz.

Nesse sentido, para além da vivência com dispositivos digitais em seu cotidiano e diferentes AVA, os professores universitários precisam apropriar-se pedagogicamente da lógica da cultura digital. Isto implica na mudança de mentalidade não apenas de professores e gestores universitários. Toda a comunidade acadêmica, os órgãos legisladores dos processos educacionais, governantes e sociedade em geral precisam repensar os modelos e estratégias de formação no ensino superior para lhes garantir 
novas competências, habilidades e valores condizentes com a realidade tecnológica, pessoal e social vigente.

Um novo ensino superior aberto, híbrido, disruptivo, multimodal, pervasivo e ubíquo voltado para o atendimento personalizado das demandas formativas dos estudantes e que seja consoante com a sociedade atual. Essas características norteiam a atual cultura digital e influenciam as necessidades de mudanças e inovações nos sistemas de educação universitária.

Algumas dessas características são tendências que podem ser verificadas também no relatório do "Horizon Report" (2017), sobre a educação superior. Dentre essas tendências, estão os projetos de ensino híbrido, ou Blended Learning, no curto prazo. No médio prazo está o redesenho dos espaços de aprendizagem, e no longo prazo está o avanço na cultura de inovação. Cabe destacar que essas três tendências se fazem presentes nos dois últimos relatórios (2016 e 2017) do "Horizon Report". Ainda segundo o relatório de 2017, entre os desafios para concretizar essas tendências, está a integração da aprendizagem formal e informal.

O ensino híbrido implica na integração entre ambientes de ensino superior presenciais e online. Institui-se a convergência de práticas de ensino e de aprendizagem, na configuração do blended learning $(\mathrm{BL})$, que modifica o conceito de presença, tanto do professor quanto do aluno. A aula se amplia e incorpora o melhor de dois ou mais ambientes - presenciais e virtuais. A redução de distâncias em ensino e aprendizagem fundamenta essa nova sala de aula, que pode transformar a universidade num lugar "sem distâncias". E sem muros e barreiras.

Essa integração é crescente, necessária e inevitável, tanto em nível micro - como uma atividade didático-pedagógica, uma disciplina ou no curso de graduação ou pósgraduação - quanto em nível macro, como em uma IES ou toda rede de ensino, incorporando as possibilidades da pervasividade e ubiquidade dos equipamentos móveis.

O ensino superior pervasivo responde a um processo de imersão, no qual as tecnologias digitais estão incorporadas à nossa vida, de tal modo que muitas vezes são imperceptíveis, como todo processo de conexão à Internet, seja por rede wireless ou por redes digitais móveis, que possibilitam o acesso ao universo online, seja ao acoplamento dos usos no nosso cotidiano e na aprendizagem.

Os LMS são um exemplo dessa pervasividade. São quase imperceptíveis suas funcionalidades, com interfaces cada vez mais intuitivas e adaptadas. Entretanto, permitem inúmeras possibilidades de ensino e de aprendizagem, como o registro estatístico de acesso, das preferências de horários de acesso dos alunos, do tempo gasto em cada atividade. Dispositivos digitais móveis com captura do movimento ótico, expressão facial e capacidade de análise dos movimentos e respostas dos usuários já tornam possíveis as condições para personalizar a aprendizagem, de acordo com interesses, necessidades e estilos de aprendizagem de cada estudante.

Como anuncia Melaré (2016), os estilos de aprendizagem são diferentes "traços cognitivos, afetivos e fisiológicos que servem como indicadores relativamente estáveis de como estudantes percebem, interagem e respondem aos seus ambientes de aprendizagem", que devem ser considerados, para ampliar a qualidade do ensino online, de modo que se motivem e sintam que estão aprendendo. Esses fatores podem 
diminuir evasão em cursos superiores online, bem como desenvolvem competências relacionadas à autonomia.

Nessa perspectiva, o digital viabiliza um ensino multimodal, posto que explora diversos modos de comunicação e expressão: fala, gesto, texto, imagem, vídeo, som, entre outros. Como espaços de convergência, os LMS possibilitam cada vez mais a integração de diferentes mídias e canais de acesso e construção dos conhecimentos propostos. São possíveis diferentes trilhas de aprendizagem, que permitem a personalização do ensino. As mais avançadas tecnologias do digital seguem no empoderamento do ser humano e lhes abre condições de interagir e aprender em diferenciadas realidades virtuais: aumentada, misturada, imersiva, simulações... garantindo a telepresença e a teleoperação.

O ensino personalizado é uma das tendências tecnológicas para ser adotada no ensino superior desde 2014, conforme o NMC Horizon Report Higher Education 2017. O relatório de 2017 aponta que é uma alternativa viável, inclusive, para equacionar o que apontam como "triângulo de ferro" dos desafios, tanto do ensino híbrido, quanto do ensino online: custo, acesso e qualidade (ADAM BECKER et al., 2017).

Essa personalização é complementada pela ubiquidade, visto que o ensino superior também pode ser adaptado para o contexto da virtualidade em aparelhos digitais móveis. A personalização do ensino se amplia com o grande número de ofertas de cursos livres e abertos disponíveis nas redes. Algumas das melhores universidades do mundo oferecem MOOCs - sigla em inglês de Massive Open Online Course (Curso Online Aberto e Massivo, na tradução literal para o português) - que são cursos abertos, de curta duração e destinados a grande número de pessoas, desenvolvidos online sobre temas específicos.

As inúmeras opções de ensino mediado via internet reconfigura o caminho tradicional de formação. Estudantes procuram as informações que são de interesse e as acessam nas redes, sem precisar ir à IES. Elas é que se oferecem e vão ao encontro das necessidades dos aprendizes. Em termos formativos, ainda que as informações sejam muito importantes, elas precisam ser contextualizadas, debatidas, discutidas e comentadas pelos que se encontram nos mesmos espaços formativos. Da discussão e reflexão coletiva surgem novas compreensões, novos posicionamentos críticos diante do conhecido. No conjunto de vozes dos sujeitos que se debruçam ao mesmo tempo diante das informações surgem novas aprendizagens. O acesso, discussão e reflexão crítica sobre estes conhecimentos distribuídos por toda parte, como diz Lèvy (2007), dá origem aos coletivos inteligentes, "já que ninguém sabe tudo, porém todos sabem alguma coisa" e, juntos, podem contribuir para a aprendizagem de uns e outros.

A formação no ensino superior em contextos digitais pressupõe a participação ativa de estudantes e professores. Reunidos nos ambientes virtuais, com aberturas para trocas informacionais e de opiniões sobre os conhecimentos e processos educativos em curso, as relações entre estudantes e professores adquirem nova roupagem, voltada para a interação, a colaboração, a organização de equipes e a superação de desafios comuns de aprendizagem.

É uma mudança na lógica do ensino, centrada no professor. Não há dúvida de que cabe a ele a orientação sobre o método e a definição do grau de interação dos aprendizes. Neste sentido, não basta a abertura sem orientação pedagógica para o processo. Ao contrário, definições prévias orientam os caminhos, a apresentação de desafios, e a personalização dos meios de aprendizagem - quando, como, com quem, 
para que... - de acordo com o contexto e as características especiais do conhecimento em questão.

O processo de formação superior que envolve a utilização dos meios digitais é necessidade urgente do contexto social, profissional e cultural em que vivemos. Para alcançar esta formação, professores e estudantes precisam estar envolvidos pelas mesmas preocupações de ensinar e aprender de forma significativa, ou seja, que seja útil e valiosa não apenas aos que participam dos momentos didáticos dos cursos, mas toda à sociedade.

O investimento social feito pela sociedade à universidade, delegando a ela a formação dos novos profissionais e cidadãos, define a relação entre o ensino mediado e a incorporação de comportamentos, conhecimentos, sentimentos e valores que sejam úteis e façam sentido nos papéis que estes aprendizes exercem ou irão exercer nas suas realidades.

A universidade não pode falar e ensinar apenas para ela mesma. Como espaço social, ela precisa estar comprometida com as características, os valores e as mentalidades do novo momento, suas necessidades e urgências. Estar empenhado com a nova cultura exige mudanças. Nesse sentido, a cultura digital exige que as IES repensem seus currículos, processos, práticas, espaços e tempos. Nesta direção, Kenski (2013, p. 73) considera que:

A revisão de currículos e práticas de formação é exigida pelas próprias associações profissionais que contabilizam o grande desgaste decorrente da necessidade de qualificação para a inserção de profissionais recém-graduados no mercado de trabalho.

Ou seja, o anacronismo curricular em relação às tecnologias acaba produzindo efeitos diretos na formação profissional, sentidos pelo egresso das IES e pelas empresas que os recebem, por terem que despender recursos com cursos de capacitação e desenvolvimento ou aprimoramento de habilidades que o sujeito já deveria possuir.

Além de reformas curriculares e revisões de processos e métodos é necessário ampliar o que se reconhece como formação. Neste sentido, a validação de cursos livres, por exemplo, é uma demanda que está posta e já está sendo discutida e considerada em muitas instituições universitárias do sistema de ensino superior europeu, regido pelo Processo de Bolonha ${ }^{5}$.

Além dessa demanda cultural, social e econômica, muitas profissões estão suscetíveis ao desaparecimento, pois as tecnologias da cultura digital estão adentrando cada vez mais não só os setores produtivos, mas a prestação de serviços em diferentes ramos ocupacionais. Essa questão tem sido pensada em diversas universidades e divulgada em múltiplos canais de comunicação. Por exemplo, no Jornal da Universidade de São Paulo, publicado em 23 de fevereiro de 2018, o professor Luli Radfahrer, pesquisador na área de Comunicação digital, afirma que muitos empregos irão desaparecer, em um curto período e em larga escala, por conta do avanço das tecnologias digitais, que envolve o uso da inteligência artificial e robótica para substituir a atuação de profissionais de diversos setores ocupacionais.

\footnotetext{
${ }^{5}$ Processo ou Tratado de Bolonha é "um acordo firmado por diversos países europeus em 1999 na cidade de Bolonha, Itália, para convergência dos sistemas de ensino superior do continente" (EIRÓ; CATANI, 2011, p. 106) e seus desdobramentos envolvem a criação do projeto Tuning, ou seja, de afinação, "que desenvolve pontos comuns de referência para currículos baseados em competências, subdivididos em diferentes áreas" (idem, p.111).
} 
Carl Frey e Michael Osborne são pesquisadores da Universidade de Oxford que também pesquisam esta temática. Segundo reportagem de Rafael Barifouse, da BBC Brasil, publicada em março de 2017, estes dois professores realizaram um estudo para tentar responder à pergunta de quais ocupações serão substituídas nas próximas duas décadas. Ao estimarem as chances para 702 profissões, descobriram que "no topo do ranking estão agente de crédito $(98,36 \%)$, analistas de crédito $(97,85 \%)$ e corretores de imóveis (97,29\%). Trabalhos como gerente de remuneração e benefícios (95,57\%), atendente em agências de correio (95,41\%) e operador de usina nuclear $(94,68 \%)$ também estão bastante ameaçados" (BARIFOUSE, 2017), bem como operador de telemarketing, que ocupou o topo do ranking, conforme o estudo.

Essa realidade atinge diretamente o ensino superior, instituição ainda reconhecida para a formação de profissionais que atuam em todas as áreas do mercado de trabalho. É preciso formar os sujeitos para esse contexto. Para as novas profissões, para as novas exigências, não são só do mercado de trabalho, mas também para as relações sociais assentadas nessa cultura da instantaneidade, da fluidez, das possibilidades de estarmos mais maquínicos, pós-humanos (SANTAELLA, 2007) e mais interativos e cônscios de que as possibilidades de aprendizagens oferecidas pelas tecnologias digitais são infinitas.

A amplitude e variedade de conteúdos e informações desorienta os aprendizes do mundo virtual, que podem se fortalecer nas trocas de informações e interações com professores e outros que possuam interesses de aprendizagem próximos aos seus. Nesse sentido, as tecnologias digitais não formulam estratégias pedagógicas e tampouco aprimoram metodologias (TAVARES, 2015). São os indivíduos imersos nesse processo que controlam e direcionam tais aprendizagens.

As tecnologias digitais usáveis em processos formativos universitários não possuem manuais ou caminhos predefinidos para utilização em atividades de ensino. Cabe aos professores rever suas práticas e integrar esses meios de acordo com as características das áreas de conhecimento e as condições de acesso e uso dos estudantes aos recursos disponíveis.

A universidade em todas as épocas tem papel essencial nessa ação formativa para os novos tempos que a sociedade está a exigir. A partir das suas ações de ensino, pesquisa e gestão de processos de formação superior, pode assumir a transformação e a inovação como suas responsabilidades, de modo a contribuir para a mudança de mentalidade, como também para refletir de forma ética e cultural sobre todo o contexto.

\section{CONSIDERAÇÕES FINAIS}

É evidente a necessidade de adotar iniciativas que sintonizem as instituições de ensino superior com os novos tempos e desafios tecnológicos. Estudantes universitários e seus professores já utilizam fortemente ampla gama de recursos digitais para atividades das mais simples às mais complexas do dia a dia.

A não adoção de uma nova mentalidade, que permita reposicionar a instituição universitária mediante o papel das tecnologias digitais no processo de ensino e aprendizagem, implica na manutenção do anacronismo dos métodos educacionais em relação à realidade contemporânea, que se reflete na baixa qualidade da educação e consequentemente em uma formação profissional precária. 
É necessário compreender que a internet e as tecnologias digitais redimensionam os papéis de professores e estudantes. Professores outrora considerados como detentores do saber, são chamados a assumir uma posição de gerenciadores, facilitadores do processo de ensino e aprendizagem. Enquanto isso os estudantes assumem postura mais ativa, na busca de informações e na atuação em equipes para examiná-las, discuti-las criticamente e seguir adiante, com inovações e novas reflexões. Essa nova postura é facilitada pelo fenômeno do fim das fronteiras entre áreas e entre conhecimentos viabilizado pelas redes de comunicação, que possibilitam ter acesso à informação ao alcance a qualquer momento e em qualquer lugar.

Para readequar as instituições de ensino a esse novo tempo, são necessárias algumas medidas básicas:

- Dotar as instituições de ensino das infraestruturas tecnológica e física necessárias;

- Reformular currículos de modo que a presença da habilidade na utilização das tecnologias digitais e seus comportamentos inovadores estejam presentes;

- Repensar a formação inicial e continuada de professores com e para a utilização das tecnologias digitais, nos processos educativos.

- Elaboração de políticas públicas integradas de inclusão digital e fluência tecnológica para todos.

- Estímulo à atuação em equipe, por meio de processos de ensino e aprendizagem interativos e colaborativos online, de forma a que a presença virtual seja mais importante e significativa do que a presença passiva dos estudantes em salas de aula presenciais.

Esses pontos são capazes de estimular uma nova cultura nas instituições de ensino. Culturas de participação, ação e inovação com a utilização intensa dos meios digitais e internet, que conectem as instituições com o ritmo e o tempo presentes de cada sujeito, seja ele professor ou estudante. Estejam na sala de aula, ou fora dela.

\section{REFERÊNCIAS}

ADAMS BECKER, Samantha et al. NMC Horizon Report: 2017 Higher Education Edition, Austin, Texas: The New Media Consortium, 2017. Disponível em: <http://cdn.nmc.org/media/2017-nmc-horizon-report-he-EN.pdf>. Acesso em: 14 jul. 2018.

BARIFOUSE, Rafael. Você corre risco de perder o emprego para um robô? BBC Brasil online. Disponível em: <https://www.bbc.com/portuguese/curiosidades-38979057>. Acesso em: 24 jul. 2018.

COSTA, Rogério. A cultura digital. 3. ed. São Paulo: Publifolha, 2008.

EIRÓ, Maria Idati; CATANI, Afrânio Mendes. Projetos Tuning e Tuning América Latina: Afinando os Currículos às Competências. Cadernos PROLAM/USP, 10, v. 1, 2011, p. 103-123.

JORNAL DA USP. O avanço da tecnologia e os empregos que deixarão de existir. Edição online de 23/02/2018. Disponível em:<https://jornal.usp.br/atualidades/o-avanco-da-tecnologiae-os-empregos-que-deixarao-de-existir/>. Acesso em: 22 jul.2018.

KENSKI, Vani Moreira. Cultura digital. In: MILL, Daniel (Org.). Dicionário Educação e Tecnologias Crítico EaD +. Campinas: Papirus, 2018.

KENSKI, Vani Moreira. A urgência de propostas inovadoras para a formação de professores para todos os níveis de ensino. Rev. Diálogo Educ., Curitiba, v. 15, n. 45, p. 423-441, mai./ago. 2015.

KENSKI, Vani Moreira. Tecnologias e tempo docente. Campinas, São Paulo: Papirus, 2013. 
KLAUS, Schwab. A quarta revolução industrial. Trad. Daniel Moreira Miranda. São Paulo: Edipro, 2016.

LEVY, Pierre. Cibercultura. Rio de Janeiro: Editora 34, 1999.

LÉVY, Pierre. Inteligência coletiva. Para uma antropologia do ciberespaço $5^{\underline{a}}$ edição ed.: Loyola, 2007.

MELARE, Daniela. Aplicação dos Estilos de Aprendizagem em Ambientes Virtuais. Simpósio virtual online. Disponível em: <https://www.youtube.com/watch?v=BRDHaYf8Xu4>. Acesso em: 11 jul. 2018

CENTRO REGIONAL DE ESTUDOS PARA O DESENVOLVIMENTO DA SOCIEDADE DA INFORMAÇÃO - CETIC. Pesquisa sobre o uso das tecnologias de informação e comunicação: pesquisa TIC Domicílios, 2017. Disponível em: <http://cetic.br/arquivos/domicilios/2017/domicilios/>. Acesso em: 21 jul. 2018.

SANTAELLA, Lucia. Desafios da ubiquidade para a educação. Unicamp, 2013. Disponível em: <https://www.revistaensinosuperior.gr.unicamp.br/>. Acesso em: 06 jun. 2018.

SANTAELLA, Lucia. Pós-humano. Por quê? Revista USP, São Paulo, n.74, p. 126-137, jun./ago. 2007.

TAVARES, Cristina Zukowsky. Educação universitária em tempos de cibercultura. Revista educação. Edição 199, 2015. Disponível em: <http://www.revistaeducacao.com.br/educacaouniversitaria-em-tempos-de-cibercultura/>. Acesso em: 9 jul. 2018.

Data da submissão: 05/12/2018

Data da aprovação: 21/02/2019 